\begin{tabular}{|l|l|l||}
\hline \multicolumn{2}{|c|}{ PublisherInfo } \\
\hline \hline PublisherName & $:$ & BioMed Central \\
\hline \hline PublisherLocation & $:$ & London \\
\hline \hline PublisherImprintName & $:$ & BioMed Central \\
\hline \hline
\end{tabular}

\title{
Sleep disorders following ICU discharge
}

\begin{tabular}{|l|l|l||}
\hline \multicolumn{2}{|c|}{ ArticleInfo } \\
\hline \hline ArticleID & $:$ & 4202 \\
\hline \hline ArticleDOI & $:$ & $10.1186 /$ ccf-2000-5359 \\
\hline \hline ArticleCitationID & $:$ & 5359 \\
\hline \hline ArticleSequenceNumber & $:$ & 61 \\
\hline \hline ArticleCategory & $:$ & Paper Report \\
\hline \hline ArticleFirstPage & $:$ & 1 \\
\hline \hline ArticleLastPage & $:$ & 3 \\
\hline \hline & $:$ & RegistrationDate : 2000-6-1 \\
ArticleHistory & $:$ & OnlineDate \\
\hline \hline ArticleCopyright & $:$ & Current Science Ltd2000-6-1 \\
\hline \hline ArticleGrants & $:$ & \\
\hline \hline ArticleContext & $:$ & 1305422 \\
\hline \hline
\end{tabular}




\section{Keywords}

Central sleep apnoea, hypoxaemia, obstructive sleep apnoea, sleep-related breathing disorder

\section{Comments}

Nocturnal hypoxaemia and sleep-related breathing disorders appear to be a frequent occurrence following discharge from the ICU in patients who had received intermittent positive pressure ventilation (IPPV) (median duration 8 days). Although a small study, it is well known that many post-operative patients experience nocturnal hypoxaemia, and it would therefore be expected that ICU patients would have similar findings since similar physiological insults exist. The majority of patients in this study suffered prolonged periods of desaturation on the ward despite oxygen therapy, and although little is known about whether this affects outcome, there is significant hospital mortality following ICU discharge. This may be because of increased ischaemic events. The fact that prolonged desaturation episodes did occur in these patients presumably implies that these patients didn't receive the oxygen they were prescribed. Central apnoea appears to be the principal mechanism behind these sleep disorders and may be a consequence of altered respiratory drive feedback control and neuromuscular weakness.Further studies are required to assess the impact of these findings on outcome. It may well be that if oxygen therapy is not easily monitored on the ward to prevent nocturnal hypoxaemia, then a stepdown unit is required for all patients who have received IPPV prior to discharge.

\section{Introduction}

There remains a significant hospital mortality for patients who survive an ICU stay and are discharged to the ward. Several studies have shown sleep disorders and nocturnal hypoxaemia in post-operative patients, which may result in ischaemic events and potential morbidity and mortality. This study examines whether these problems may exist in patients discharged from the ICU.

\section{Methods}


- Prospective, consecutive patient study $(n=15)$ performing overnight pneumographic sleep studies, simple spirometry and Epworth sleepiness score (ESS) on patients who had received more than 48 $h$ of IPPV in the ICU.

- Studies performed on the ward within $72 \mathrm{~h}$ of discharge from the ICU.

- Control group ( $\mathrm{n}=10$, fit, healthy, volunteers) underwent identical studies.

- Abnormal respiratory events recorded and identified as obstructive, central or hypopnoeas.

- Exclusions: known sleep apnoea, COPD, CCF, neuromuscular disorders.

\section{Results}

The control group showed a normal ESS, normal pneumographic studies, no significant oxygen desaturations, and had a body mass index (BMI) in the normal range. In the patient group, sedation and analgesia had been provided with various combinations of propofol, midazolam, morphine and fentanyl, whilst in the ICU. All patients had a normal ESS. The majority of patients who were able to perform spirometry showed significant reductions in both forced expiratory volume 1 and forced vital capacity. Three patients had BMI $>25 \mathrm{~kg} / \mathrm{m}^{2}$ and one patient had a BMI $>30 \mathrm{~kg} / \mathrm{m}^{2}$. Oxygen therapy was prescribed to all patients, but $13 / 15$ patients still had episodes of nocturnal hypoxaemia. Nine patients had $\mathrm{SaO}_{2}<90 \%$ for longer than $2 \mathrm{~h}$. The number of patients with pneumographic abnormalities differs between the text and table in the actual paper but it appears that the majority had respiratory events and they were predominantly hypopnoeas in origin. Three out of four patients with a high BMI had obstructive apnoeas, but hypopnoeas also occurred.

\section{References}

1. Chishti A, Batchelor AM, Bullock RE, Fulton B, Gascoigne AD, Baudouin SV: Sleep-related breathing disorders following discharge from intensive care. Intensive Care Med. 2000, 26: 426-433.

This PDF file was created after publication. 